\title{
Studies on bovine and ovine rumen fluid urease
}

\author{
A. Moharrery ${ }^{1}$ \\ Animal Science Department, Agricultural College, Shahrekord University, Iran
}

\begin{abstract}
Rumen fluids were collected from a slaughterhouse. Mixed rumen contents of sheep and Holstein cows were transported to the laboratory in thermos flasks, separately for each species. Ammonium sulphate and acetone were used for precipitation of protein in cell free rumen fluid. The precipitate that was observed after freezing and thawing of cell free rumen fluid and precipitate, obtained with $25 \%$ saturated ammonium sulphate showed no urease activity. Urease activity in precipitates from $80 \%$ saturated ammonium sulphate for cows and sheep were 3.61 and 6.17 (microgram ammonia$\mathrm{N}, \mathrm{mg}^{-1}$ protein. $\mathrm{min}^{-1}$ ), respectively. These amounts for acetone precipitate for cow and sheep were 1.88 and 0.48 , respectively. Sodium dodecyl sulphate (SDS) acrylamide gel electrophoresis indicated the same subunit urease enzyme for sheep and cow. The molecular weight of rumen urease subunit was estimated to 75000 daltons, which is less than jack-bean urease (96000 daltons). Native urease did not separated by $3.2 \%$ acrylamide gel electrophoresis. The latter finding may indicate that rumen urease has a hexameric structure with more than 1500 kilodaltons.
\end{abstract}

KEY WORDS: sheep, cow, rumen, urease

\section{INTRODUCTION}

Urease is a nickel-containing enzyme that catalyses the hydrolysis of urea to form ammonia and carbamate. The latter compound spontaneously decomposes to generate a second molecule of ammonia and carbon dioxide. Bacterial urease plays an important role in ruminal nitrogen metabolism. Urea, supplied in the diet or recycled from saliva and the bloodstream, is hydrolysed to yield ammonia. The ammonia is then combined with ketoacids by the microbes to produce amino acids. Urease in the rumen will continue to convert urea to ammonia even if there is a lack of ketoacids. If the rate of ammonia production (i.e. urea via urease breakdown to ammonia) or ingestion of ammonia (i.e. ammoniated feeds) exceeds the microbes ability to utilize it to form amino acids, there is an accumulation of ruminal ammonia. The liver via the urea cycle normally detoxifies ammonia

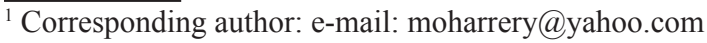


absorbed from the rumen into systemic circulation. This detoxification system can be overwhelmed resulting in elevated blood ammonia levels. In order to be able to control the activity of urease in the rumen, detailed knowledge about rumen urease is needed. In spite of the importance of the rumen urease in the physiology and nutrition, few studies are available. The presents report attempt to describe some of the properties of rumen urease.

\section{MATERIAL AND METHODS}

Rumen fluids (one litre) were collected from an abattoir immediately after slaughtering animals. Mixed rumen content from native sheep and Holstein cows was squeezed through four layers of cheesecloth (separately for each species) and transported to the laboratory in thermos flasks. All subsequent operations were conducted in cool condition (near to $4^{\circ} \mathrm{C}$ ). The rumen fluid was centrifuged at $6000 \times \mathrm{g}$ for $45 \mathrm{~min}$ and the clear supernatant was kept frozen overnight $\left(-20^{\circ} \mathrm{C}\right)$. Next day, half part of the supernatant was fractionated with ammonium sulphate and another part precipitate with 30\% acetone (separately for each species). The precipitates obtained with 25 to $80 \%$ ammonium sulphate and acetone were dissolved in sodium phosphate buffer $\mathrm{pH}=7$ and subjected to heat treatment $\left(20 \mathrm{~min}\right.$ in $\left.55^{\circ} \mathrm{C}\right)$. The mixture was centrifuged at $6000 \times \mathrm{g}$ for $50 \mathrm{~min}$ and supernatant was stored frozen at $-80^{\circ} \mathrm{C}$.

Acrylamide gel electrophoresis for urease

The supernatant was analysed at $4^{\circ} \mathrm{C}$ by acrylamide gel electrophoresis at $\mathrm{pH}$ 8.3 on 7.5 and $3.2 \%$ gel for native enzyme and electrophoresis was also done at pH 8.3 on 4\% SDS-polyacrylamide gel. The SDS-polyacrylamide gel was stained with silver nitrate.

Assay of urease

Measurement of urease activity was done according to Moharrery and Das (2001).

\section{RESULTS AND DISCUSSION}

\section{Urease assay}

After freezing and thawing in the first step of sample preparation, a medium amount of precipitate was formed. This precipitate showed no urease activity. Precipitate, which was obtained with $25 \%$ ammonium sulphate showed very weak urease activity. In this regard, the precipitate formed after heat treatment showed no urease activity. The results from urease assay are presented in Table 1 . This Table shows that the procedure for precipitation could be a factor, which 
affect urease activity in each species. In cows rumen fluid the urease precipitate with acetone, showed higher urease activity than sheep rumen fluid, but precipitate from ammonium sulphate in cows rumen fluid, showed less urease activity compared to sheep rumen fluid under the same condition. Generally the procedure with acetone precipitation has been shown not to be suitable for enzyme purification and enzymes will lose their activity due to acetone action on enzyme protein denaturation, which cannot renaturate after disappearance of the acetone effect.

Table 1. Urease activity in preparations from Jack-bean or rumen fluid

\begin{tabular}{llcc}
\hline Species & Precipitation & $\begin{array}{c}\text { Total } \\
\text { activity }^{\mathrm{a}}\end{array}$ & $\begin{array}{c}\text { Specific } \\
\text { activity }^{\mathrm{b}}\end{array}$ \\
\hline Jack-bean & & 24.73 & 3.65 \\
\multirow{2}{*}{ Sheep } & Acetone $^{\mathrm{c}}$ & 2.84 & 0.48 \\
& Ammonium sulphate $^{\mathrm{d}}$ & 17.91 & 6.18 \\
\multirow{2}{*}{ Cow } & Acetone $^{\mathrm{c}}$ & 4.95 & 1.88 \\
& Ammonium sulphate $^{\mathrm{d}}$ & 13.47 & 3.60 \\
\hline
\end{tabular}

a - $\mu$ g ammonia-N min $^{-1}$

${ }^{\mathrm{b}}-\mu \mathrm{g}$ ammonia-N $\min ^{-1} \cdot \mathrm{mg}^{-1}$ protein

c - urease precipitated with $30 \%$ acetone

d- urease precipitated with 25 to $80 \%$ ammonium sulphate

\section{Gel electrophoresis}

The native urease enzyme from both species has not been separated by the acrylamide gel electrophoresis at $\mathrm{pH} 8.3$ on 7.5 and $3.2 \%$ gel for native enzyme. The molecular weight for urease enzyme is near to $300 \mathrm{kDa}$, which can form a hexameric structure with more than $1500 \mathrm{kDa}$. In this condition separation of urease by gel electrophoresis, as explained earlier is not possible. When these type gels were stained catalytically for urease activity after electrophoresis, only band of urease activity appeared in the top of the gel, which indicated no separation has occurred during electrophoresis due to high molecule weight. These results are in contrast to the finding of Mahadevan et al. (1976) in which they separated bovine rumen enzymes by $7 \%$ acrylamide gel electrophoresis.

The subunit relative molecular mass for Jack-bean urease along with four types rumen urease were determined by using SDS-polyacrylamide gel electrophoresis. As shown in Figure 1, the rumen urease beside of species kind or procedure for precipitation, is homogeneous and has a subunit molecular weight of near to $75000 \mathrm{Da}$. The subunit molecular weight for rumen urease is less than Jack-bean urease (75 vs $96 \mathrm{kDa}$ ). The result of this report is agree with Hausinger (1986) who has reported $70000 \pm 2000$ daltons molecular weights for urease which is purified from S. ruminantium. 


\section{$\begin{array}{llllll}1 & 2 & 3 & 4 & 5 & 6\end{array}$}

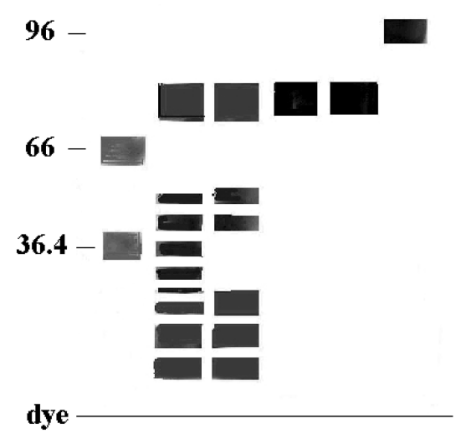

Figure 1. Sodium dodecyl sulphate-polyacrylamide gel electrophoresis of urease. The gel was stained with silver nitrate and the dark area has been omitted from the figure for better view. Y axis shows molecular weight in $\mathrm{kDa}$. Lines one to six are, standards, sheep, cow (ammonium sulphate), sheep, cow (acetone) and Jack-bean urease, respectively

\section{REFERENCES}

Hausinger R.P., 1986. Purification of a nickel-containing urease from the rumen anaerobe Selenomonas ruminantium. J. Biol. Chem. 261, 7866-7870

Mahadevan S., Sauer F., Erfle J. D., 1976. Studies on bovine rumen bacterial urease. J. Anim. Sci. 42, 745-753

Moharrery A., Das T.K., 2001. Correlation between microbial enzyme activities in the rumen fluid of sheep under different treatments. Reprod. Nutr. Develop. 41, 513-529 